\title{
Auditoria de avaliação das não conformidades relativas à NR-18 e seu impacto no custo de empreendimentos do subsetor edificações
}

Luiza Lopes Carvalho

Universidade Federal Fluminense (UFF),

Niterói, Rio de Janeiro, Brasil

João Alberto Neves

joaoalbertoneves@gmail.com

Universidade Federal Fluminense (UFF)

Niterói, Rio de Janeiro, Brasil

\begin{abstract}
RESUMO
A indústria da Construção Civil é um dos setores que apresentam as piores condições de segurança e consequentemente o maior número de acidentes de trabalho todos os anos. Dentre os fatos que justificam essa realidade tem-se a falta de cumprimento da lei ou regulamentação adequada de segurança. Diante desse cenário, é necessário que os empregadores formem uma consciência sobre o problema, implementando alternativas eficazes para o seu enfrentamento, dentre elas a implantação de programas de prevenção. É um fato incontestável que inúmeros acidentes seriam evitados, se as empresas adotassem os princípios mínimos de segurança presentes na Norma Regulamentadora NR-18. Ela estabelece diretrizes que objetivam a implantação de medidas de controle e sistemas preventivos de segurança no meio ambiente de trabalho da indústria da Construção, que deveriam estar presentes nos arranjos físicos dos canteiros. Dessa forma, o presente artigo tem como objetivo aplicar um instrumento qualitativo, em 31 canteiros de obras da cidade de Macaé, que contribua para a avaliação de elementos críticos em Programas de Avaliação das Condições de Trabalho da Indústria da Construção Civil. Além disso, quantificar as possíveis multas a serem pagas pelo não cumprimento da NR-18 e fazer comparações com o valor que deve ser investido para que as empresas de estudo consigam adequar suas não conformidades, de forma a comprovar que, em média, é menos custoso para a empresa investir em segurança do trabalho, do que ficar sujeita ao pagamento de multas que aumentem significativamente os custos finais do empreendimento.
\end{abstract}

PALAVRAS-CHAVE: Construção civil. Segurança do trabalho. NR-18. NR-28. 


\section{INTRODUÇÃO}

A indústria da construção civil desempenha um importante papel no desenvolvimento econômico e social de um país, devido à sua extensa cadeia produtiva. Ela funciona como um dinamizador da economia, com grande capacidade de geração de riquezas e empregos. Entretanto, o setor é um dos maiores responsáveis pelo grande número de acidentes de trabalho que ocorrem todos os anos no país.

Os últimos dados levantados pelo Anuário Estatístico da Previdência Social apontam que em 2015 ocorreu um total de 612,6 mil acidentes no país, dentre os quais 41.012 são relativos à indústria da construção civil, o que representou 6,69\% do total ocorrido no ano em todos os setores da economia (AEPS, 2015).

Embora esses índices sejam alarmantes, eles ainda não representam a grandeza do problema vivido pelo setor, devido ao alto grau de subnotificação das informações sobre os acidentes. Ou seja, grande parte dos acidentes não é registrada através da CAT (Comunicação de Acidente de Trabalho), o que faz com que eles não sejam contabilizados nas estatísticas.

Tendo em vista as características do setor, podemos compreender o porquê da construção civil apresentar em todo o mundo, e não só no Brasil, índices de acidentes tão elevados (WAEHRER et al., 2007).

Como o arranjo físico da construção civil é do tipo posicional, aquele em que o produto é instalado em um lugar fixo enquanto os materiais e equipamentos se movimentam, os trabalhadores estão sujeitos a grandes riscos de acidentes devido à maior frequência de cruzamento dos movimentos nas tarefas a serem executadas. Além disso, fatores como operários mal remunerados e deficientemente capacitados e exigência com a qualidade e rapidez na execução dos serviços também fazem com que as atividades nessa área sejam potencialmente geradoras de acidentes.

Dentre os riscos em que o trabalhador esta exposto, podemos citar os riscos do ambiente, das intempéries, de suas tarefas e das atividades em conjunto com outros trabalhadores (ENSSLIN, 2014). Esses riscos possuem especificidades e intensidades que variam de acordo com o tipo de construção, com a etapa da obra e com a importância que é dada aos programas e ações de segurança do trabalho (ILO, 2014).

Esse elevado número de acidentes de trabalho ocorridos no setor de construção civil, todos os anos, tem trazido à tona a questão da obrigatoriedade do cumprimento das normas de segurança, como, por exemplo, da Norma Regulamentadora n. 18 (NR-18), específica para a indústria da construção (BRASIL, 2014).

A criação da NR-18 foi decisiva na trajetória dos trabalhadores ao longo das últimas décadas, estabelecendo diretrizes de ordem administrativa, de planejamento e de organização, visando à implementação de medidas de controle e sistemas preventivos de segurança nos processos, nas condições e no meio ambiente de trabalho na indústria da construção (BRASIL, 2014).

Apesar da legislação de segurança ser de caráter obrigatório, os empregadores ainda encontram dificuldades para cumpri-la, bem como em contribuir para a criação e manutenção de uma cultura de saúde e segurança nos 
canteiros de obra. Para que seja possível reduzir o número de acidentes no setor é necessário um maior investimento em fiscalização, prevenção e conscientização dos funcionários.

Dentro deste contexto, e considerando os custos inerentes a negligência com a saúde e segurança do trabalhador, o presente artigo objetiva auditar 31 canteiros de obras da cidade de Macaé, de forma a verificar o nível de adequação dos mesmos aos requisitos presentes na norma NR-18, identificando quais itens são mais negligenciados.

Além disso, levantar dados relacionados ao custo da multa por descumprimento da NR-18, que comprovem o fato de que a prevenção é a melhor solução a ser seguida pelas empresas.

\section{REVISÃO DA LITERATURA}

\section{DEFINIÇÕES REFERENTES À SEGURANÇA DO TRABALHO}

A gestão da segurança e saúde no trabalho consiste em conjunto de medidas e ações preventivas adotadas com o intuito de reduzir os acidentes do trabalho, doenças ocupacionais, bem como proteger a integridade e a capacidade de trabalho nas atividades das empresas ou estabelecimentos (CHIAVENATO, 1999; MARTINS, 2004; ATLAS, 2014; NUNES, 2016).

Desta forma, ao analisar antecipadamente os potencias riscos existentes em determinada atividades, pode-se prevenir contra acidentes já conhecidos (RIGOLON, 2013).

Além do mais, de acordo com Campos (2014):

A Segurança e Medicina do Trabalho preocupa-se com todas as ocorrências que interfiram em solução de continuidade em qualquer processo produtivo, independente se nele tenha resultado lesão corporal, perda material, perda de tempo ou mesmo esses três fatores conjuntos. A prevenção de acidentes só pode ser bem realizada a partir de um programa consistente, que contenha objetivos muito claros e que leve em conta desde um pequeno incidente até um acidente com graves repercussões.

\section{ACIDENTES DE TRABALHO}

Segundo os dados da OIT (2017) - Organização Internacional do Trabalho, cerca de 2,3 milhões de pessoas morrem e 300 milhões ficam feridos todos os anos no mundo em acidentes de trabalho. Em 2001, os acidentes de trabalho mataram 2 vezes mais que os conflitos armados. Foram mortas 650 mil pessoas em conflitos armados e 1 milhão e 300 mil pessoas mortas em acidentes de trabalho (IBGE, 2013).

A NBR 18801 - Sistema de gestão da segurança e saúde no trabalho define acidente de trabalho como um evento ou conjunto de eventos de ocorrências anormais, ou qualquer intervenção no processo normal de trabalho, que 
resultem em consequências que possam causar lesões ao trabalhador (ABNT, 2011).

Rigolon (2013) reforça que os acidentes do trabalho são fenômenos previsíveis, portanto podem ser adotadas medidas de prevenção com o intuito de minimizar ou evitar a repetição de episódios semelhantes e a ocorrência de novos incidentes.

\section{CAUSAS DE UM ACIDENTE DE TRABALHO}

Um acidente de trabalho raramente é originado por apenas um fator, mas sim por um conjunto de eventos que acabam levando a um prejuízo (ZARPELON et al., 2008).

lida (2005) considera a má interação entre homem, atividade executada e ambiente de trabalho, as causas dos acidentes laborais. Ela rotula essas causas como: modelos Sequencias e Fatoriais. Segundo ela, os modelos Sequenciais consideram que um acidente possui múltiplas causas e que ele ocorre em uma sequência lógica e fixa de eventos.

De acordo com a "Teoria do Dominó" de Heinrich, o modelo Sequencial mais referenciado, esta sequência pode ser dada pelos seguintes fatores: a) comportamentos indesejáveis herdados ou adquiridos do meio (personalidade); b) Falha humana; c) Ato inseguro e/ou condição insegura; d) Acidente; e) Lesão , como pode ser visto na figura 1 (SAURIN, 2002).

Figura 1 - Sequência de acontecimentos de um acidente - Teoria do Dominó, Heinrich

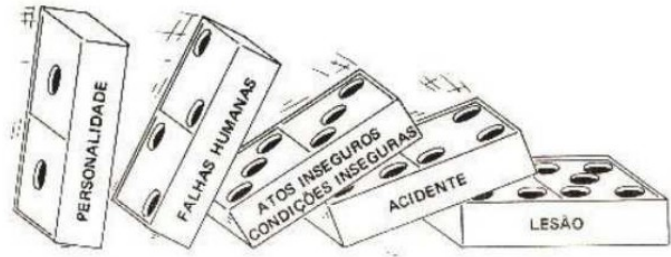

Fonte: IIDA (2005)

Dessa forma, a teoria do dominó considera que ao extrair um dos fatores de risco, a cadeia se quebraria e o acidente poderia ser evitado, como mostra a figura 2 (SAURIN, 2002).

Figura 2 - Interrupção da sequência de acontecimentos - Teoria do Dominó, Heinrich

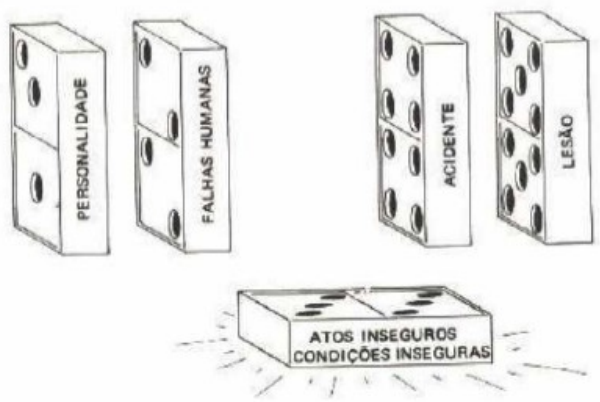

Fonte: IIDA (2005) 
Já os modelos Fatoriais não consideram que haja uma sequência lógica ou temporal de eventos, contudo, pondera a existência de um agrupamento de fatores que interagem entre si de forma contínua e aleatória podendo ocasionalmente, levar a um quase acidente ou um acidente. Este é o modelo mais aceito nos dias de hoje (IIDA, 2005).

\section{ACIDENTES DE TRABALHO NA CONSTRUÇÃO CIVIL.}

Segundo o Ministério do Trabalho e Emprego (MTE, 2011), a indústria da Construção Civil é um dos setores que apresentam as piores condições de segurança e conseqüentemente o maior número de acidentes de trabalho no país.

No ranking de lesões, as quedas e ferimentos nos membros superiores (mãos) são os mais frequentes entre os trabalhadores. Já nos casos de óbitos, os registros mostram quedas de grandes alturas e eletricidade como principais motivos (Ramazzini, 2015).

Tal cenário deve-se a diversos fatores, dentre eles, à falta de sistemas de gestão da segurança e saúde eficazes, à reduzida padronização do trabalho associado às frequentes improvisações e à tempestividade dos processos decisórios, os quais têm gerado na indústria da construção, um número de acidentes incompatível com as demais atividades produtivas no Brasil (ENSSLIN et al., 2014).

Outro fator que também contribui com o elevado índice de acidentes é a maneira que o trabalho é organizado, estando presentes condições inseguras, inadequação dos equipamentos, falta de informação e preparo dos envolvidos nas obras, exigindo do funcionário o desenvolvimento de habilidades particulares que contribuam para sua segurança (DIEESE, 2011).

É fundamental que, devido à natureza particular da atividade da indústria da construção civil, sistemas de gestão específicos sejam utilizados, de modo a atender às suas necessidades. Dessa forma, as empresas não só vão garantir sua sobrevivência em um mercado cada vez mais competitivo, mas também a melhoria da qualidade de seus produtos e sua melhor adequação aos novos valores sociais emergentes (SILVA et al. 2014).

\section{NR-18}

Com o intuito de melhorar as condições de segurança do trabalho e reduzir o alto índice de acidentes e de óbitos na construção civil, o Ministério do Trabalho criou a NR 18 - Condições e Meio Ambiente de Trabalho na Indústria da Construção, ainda que todas as NR sejam aplicáveis à construção.

Ela estabelece diretrizes de ordem administrativa, de planejamento e de organização, que objetivam a implantação de medidas e controle e sistemas preventivos de segurança nos processos, nas condições e no meio ambiente de trabalho na indústria da construção, que deveriam estar presentes nos arranjos físicos dos canteiros de obra (WELTER, 2014). 
O programa que coloca os objetivos da NR 18 em prática é o Programa de Condições e Meio Ambiente de Trabalho (PCMAT), plano que estabelece condições e diretrizes de Segurança do Trabalho para obras e atividades relativas à construção civil (SIMON, 2012).

Este programa tem como finalidade, além da adoção de uma ferramenta que busca a preservação da saúde e da integridade física dos trabalhadores, manter o controle de todos os agentes ambientais, com monitoramentos periódicos, contendo as etapas de antecipação, reconhecimento, avaliação e consequente controle da ocorrência de riscos ambientais existentes ou que venham a existir no ambiente de trabalho, devendo ser elaborado por profissional legalmente habilitado na área de segurança do trabalho, sendo sua prática nos estabelecimentos, responsabilidade do empregador (SIMON, 2012).

NR- 28

De acordo com Welter (2014), estudos realizados recentemente evidenciam que, apesar do cumprimento da Norma Regulamentadora 18 ser de observância obrigatória e a fiscalização do Ministério do Trabalho e Emprego (MTE) ter autoridade plena para aplicar autos de infração e até mesmo embargar obras que ofereçam riscos iminentes aos trabalhadores, ou que não atendam aos requisitos da mesma, muitas empresas ainda encontram obstáculos para colocála em prática nos seus canteiros de obra (Brasil, 2015).

Dentre os fatos que justificam essa realidade, tem-se a falta de planejamento das atividades, a visão errada sobre o custo de se investir em segurança do trabalho e falta de conscientização de sua importância, uma vez que algumas das exigências da norma são de baixo custo, breves e simples de serem executadas nas próprias obras (FILGUEIRAS, 2015).

Devido à necessidade de sobrevivência em um mercado cada vez mais competitivo, muitas empresas vêm concentrando seus esforços no controle dos custos e aumento da produtividade, negligenciando muitas vezes o controle dos riscos, favorecendo assim, a ocorrência de acidentes, e consequentes prejuízos (BLANCO, 2016).

A segurança do trabalho, porém, deve ser abordada pela empresa, como investimento e não como custo, uma vez que a ocorrência de um acidentes de trabalho implica em uma elevada perda para toda a sociedade, devendo ser a sua redução uma preocupação do governo, de empresários e trabalhadores (GURCANLI, BILIR e SEVIM, 2015).

Além do lado social, devido às mortes e mutilações de operários, a importância econômica também é crescente, por conta do maior gasto do governo com Previdência Social, Sistema Único de Saúde (SUS) e custos judiciários, dos custos diretos e indiretos relacionados aos acidentes e dos altos custos com multas, devido ao não cumprimento das normas de segurança em vigor (ENSSLIN, 2014). O valor dessas multas pode interferir claramente nos dispêndios da obra, através de custos que não estavam previstos em orçamento, prejudicando o andamento da mesma (FILGUEIRAS et al, 2015).

Essas multas são aplicadas a partir da Inspeção de Agentes do Trabalho, que visitam as instalações e/ou canteiros de obra da empresa, visando fiscalizar o 
cumprimento das normas regulamentadoras. Dessa forma, é importante a conscientização das empresas sobre sua responsabilidade em promover um ambiente de trabalho dentro dos padrões estabelecidos, pois a aplicação da multa não a desobriga de se adequar a legislação de segurança e medicina do trabalho (FILGUEIRAS et al, 2015).

Os assuntos relacionados á fiscalização do cumprimento das disposições legais e/ou regulamentares sobre segurança e saúde do trabalhador são tratados na Norma Regulamentadora 28 - Fiscalização e Penalidades. Essa norma tem como objetivo preservar o ambiente laboral saudável e sem riscos para a vida dos colaboradores (BRASIL, 2015).

Dessa forma, além de prezar pela vida dos trabalhadores, o investimento em medidas preventivas de segurança do trabalho, preza também pela redução de elevados custos para a empresa (ENSSLIN, 2014). Logo, para que seja possível reduzir o número de acidentes no setor é necessário um maior investimento em fiscalização, prevenção e conscientização dos funcionários.

\section{MÉTODO}

O presente trabalho pode ser classificado quanto aos seus fins como uma pesquisa Descritiva, pois tem como objetivo principal descrever características da população de estudo referentes à NR-18, e Explicativa, pois busca elucidar quais fatores auxiliam, de alguma forma, a ocorrência de acidentes de trabalho.

Em termos de categorização da pesquisa segundo o seu Meio, ou seja, procedimento técnico utilizado pode-se dizer que este trabalho é classificado como uma Pesquisa de Campo e um Estudo de Caso. Pesquisa de Campo devido á realização de investigações presenciais nos canteiros de obra, e Estudo de Caso em virtude da necessidade de um estudo aprofundado e detalhado das condições de segurança das empresas de Construção Civil selecionadas.

Por fim, em relação à Abordagem, foram realizadas análises tanto Qualitativas, quanto Quantitativas no presente estudo. O enfoque Qualitativo foi empregado na investigação e descrição do local e das condições de trabalho dos canteiros e o Quantitativo, na avaliação do nível de adequação das condições de trabalho das empresas avaliadas, aos requisitos presentes na Norma de segurança NR-18, no cálculo das multas e dos custos de adequação.

Na primeira etapa desse trabalho foi realizada uma análise crítica de algumas publicações existentes sobre Saúde e Segurança do Trabalho na Construção Civil, de forma a obter um embasamento para a execução do mesmo. Dessa forma, essa revisão bibliográfica foi de grande valia para a compreensão da relevância do tema abordado.

Através dessas publicações foram encontradas algumas listas de verificação referentes ao cumprimento da NR-18 (BRASIL, 2015), porém a escolhida para a avaliação das condições de trabalho dos canteiros de obras de estudo foi o Check-list "Programa de Avaliação das Condições de Trabalho da Indústria da Construção Civil", devido ao fato desse instrumento ser o utilizado pelos agentes da inspeção do trabalho em fiscalizações do Ministério do Trabalho e Emprego. 
Considerando a significativa extensão da NR-18 e a sua orientação para diferentes fases de uma obra, esse instrumento foi adaptado, de forma a contemplar os itens das seguintes categorias:

- $\quad$ Ambiente de trabalho

- $\quad$ Área de vivência

- $\quad$ Escadas, Rampas e Passarelas

- Medidas de proteção contra quedas de altura

- $\quad$ Andaimes e Plataformas de Trabalho

- $\quad$ Equipamento de Proteção Individual - EPI

- Treinamento

- $\quad$ Ordem e Limpeza

- Sinalização

Essa medida objetivou avaliar os itens mais críticos da Norma para as etapas de superestrutura em diante, ou seja, a parte da estrutura de uma edificação que se projeta acima da linha do solo, devido ao fato dos canteiros selecionados se encontrarem em etapas semelhantes a esta ou mais avançadas.

Para o julgamento das condições de segurança de cada categoria analisada nos canteiros de estudo, foi utilizado o método de avaliação pelo questionamento de SIM e NÃO. O "Checklist" escolhido possui os itens da NR-18 discriminados e numerados, seguidos de três alternativas: "SIM", quando o item analisado estiver de acordo com a norma, "NÃO", quando o item não atender ao requisito da norma e "NÃO SE APLICA", quando o item não se aplicar à atual fase obra, assim como mostra a figura 3.

Quadro 1 - Exemplo de configuração e requisitos da lista de verificação.

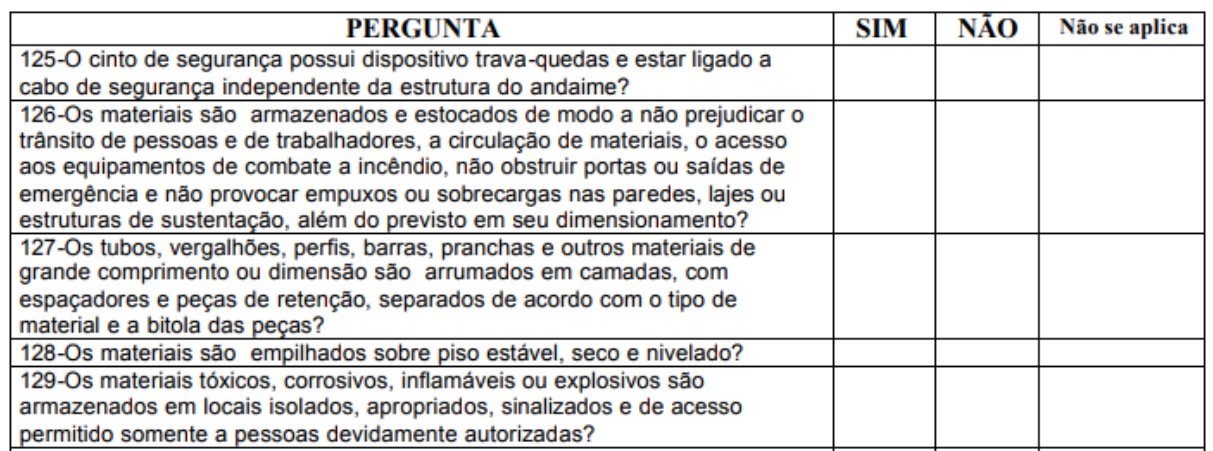

Fonte: Comissão Interinstitucional de Prevenção aos Acidentes de Trabalho e Doenças Ocupacionais, Ministério do Trabalho e Emprego (2003)

Quanto maior for à quantidade de respostas SIM, melhores as condições de trabalho da categoria analisada, e quando uma pergunta não for aplicável, não contará para a pontuação, sendo o resultado adaptado ao no de questões aplicáveis na forma de percentual. Dessa forma, a nota obtida por uma obra, ou seja, o nível de adequação da variável analisada, corresponde à razão entre o total de itens "Sim" e o total de itens "Sim" e "Não", do item analisado, multiplicados por dez para que a nota final seja tabulada em uma escala que varia de zero a dez, conforme a Equação 1:

$$
\text { Nota }{ }_{\text {Item }}=\operatorname{Sim\times 10/(Sim+Não)(1)}
$$


Considerando que uma amostra é escolhida para representar a população à qual pertence, foi realizada nesse estudo uma amostragem não-probabilística por Conveniência, que é justificada por ser o tipo de amostragem mais comum em estudos onde fatores como a proximidade geográfica das informações, disponibilidade de tempo do pesquisador, fácil acesso aos dados e vontade do pesquisado de se voluntariar, são considerados (FARROKHI E MAHMOUDIHAMIDABAD, 2012). Ou seja, é a amostragem onde os elementos da população são selecionados por conveniência do pesquisador.

Esta forma de amostragem é classificada como Não-Probabilística, pois por não termos acesso ao tamanho da população existente, a probabilidade de seleção da amostra é desconhecida. Dessa forma, a escolha dos canteiros foi feita baseada nos critérios e julgamentos da autora.

A seleção da amostra de estudo teve inicio a partir da realização de uma pesquisa dos telefones das construtoras que estão em atuação na cidade de Macaé. Após essa etapa, foram realizados contatos com as mesmas, objetivando sensibilizá-las a respeito deste trabalho e conseguir uma aprovação para que as visitas nos canteiros fossem realizadas.

A fim de que o perfil de uma empresa não predomine sobre o restante, resolveu-se estabelecer o limite de três obras por empresa. Além disso, foram excluídas as construtoras que não possuíam canteiros de obras do subsetor de edificações em atividade.

Antes que as visitas técnicas fossem realizadas, foi feito um levantamento dos endereços de todos os canteiros das empresas que se dispuseram a colaborar com a pesquisa, como pode ser visto na figura 4. Dessa forma, foi possível realizar um planejamento dessas visitas com o intuito de avaliar de acordo com sua localização, quantos e quais canteiros seriam avaliados por dia, otimizando assim, o tempo dos pesquisadores.

Figura 3 - Localização dos 31 canteiros de obra avaliados

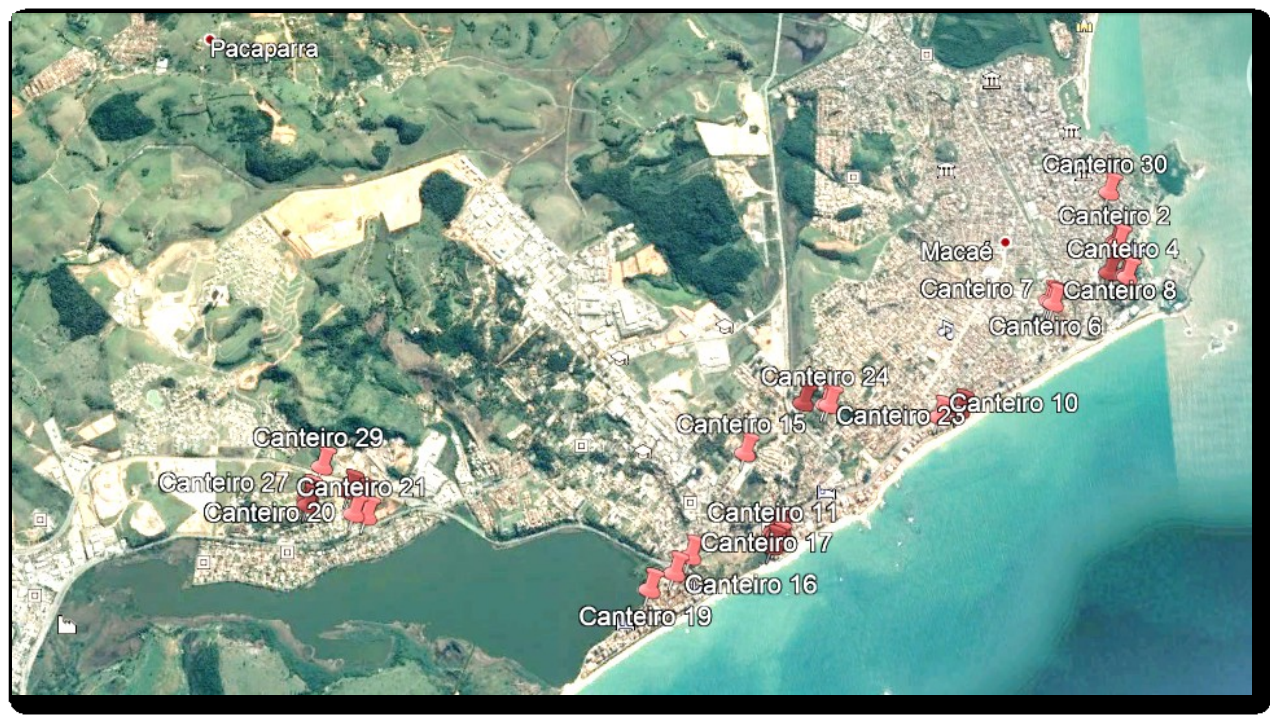

Fonte: A autora (2017) 
A pesquisa, então, foi desenvolvida tendo por base 31 canteiros de obras de edificações residenciais e/ou comerciais, de 23 empresas diferentes na cidade de Macaé, RJ.

Com o instrumento de pesquisa elaborado, a amostra definida e os canteiros mapeados foi possível então, dar início à etapa de coleta dados.

O check-list foi aplicado com a autorização do respectivo responsável de cada obra, durante uma visita técnica que teve uma duração média de 40 minutos por canteiro. As variáveis que tornaram este tempo maior ou menor foram o porte da obra e a disponibilidade do entrevistado. Quanto maior o porte da obra, maior o tempo de identificação dos itens do check-list e quanto maior a disponibilidade do entrevistado, maior o tempo gasto para explorar o máximo de informações que ele pudesse fornecer.

Também foi solicitada aos mesmos uma autorização para que registros fotográficos fossem feitos, com o intuito de apresentar exemplos de boas e más práticas em segurança do trabalho. Porém, nem todas as empresas permitiram os registros.

Entrevistas com os responsáveis pelas obras foram realizadas após a aplicação do check-list com o intuito de extrair informações e detalhes que não foram possíveis de serem levantados visualmente.

Essas entrevistas foram feitas de forma aberta, ou seja, requerendo uma resposta completa dos entrevistados, usando seus próprios conhecimentos e experiências, aumentando assim a compreensão acerca do atual estágio de desenvolvimento da segurança do trabalho de cada empresa.

Depois de identificados os itens não conformes com a NR-18, de cada canteiro de estudo, foi possível dar início á etapa de análise dos dados.

Para que fosse possível classificar as condições de trabalho de cada canteiro de obras como Péssima, Ruim, Regular, Boa e Ótima, foram utilizados os percentuais abaixo, calculados através da equação $x$, como parâmetros:

- $\quad$ Péssimo - 0 a $20 \%$

- $\quad$ Ruim - 20,1 a $40 \%$

- Regular - 40,1 a 60\%

- Bom - 60,1 a $80 \%$

- Ótimo - 80,1 a $100 \%$

Foram obtidas notas e classificações globais por canteiro de obra e parciais por categoria analisada da NR-18, que permitiram comparações entre obras e empresas, tanto na visão geral, quanto entre os tópicos semelhantes.

Segundo a NR-28, as multas são calculadas através do cruzamento entre o número de funcionários e o código da infração. Para saber o código da infração, que varia de 1 a 4, é necessário consultar no Anexo II da NR-28, o item ou subitem da NR-18 que foi infringido, como pode ser visto na figura 5 . 
Quadro 2 - Parte da tabela referente ao Código de Infração da NR-18

\begin{tabular}{|l|c|c|}
\hline \multicolumn{3}{|c|}{ NR 18 (218.000-6) } \\
\hline Item/Subitem & Código & Infração \\
\hline 18.1 .3 & $218001-4$ & 3 \\
\hline 18.2 .1 & $218002-2$ & 1 \\
\hline 18.3 .1 & $218003-0$ & 4 \\
\hline 18.3 .1 .1 & $218004-9$ & 2 \\
\hline 18.3 .1 .2 & $218946-1$ & 1 \\
\hline 18.3 .2 & $218947-0$ & 2 \\
\hline 18.3 .3 & $218007-3$ & 3 \\
\hline 18.3 .4$. a & $218008-1$ & 3 \\
\hline 18.3 .4$. b & $218009-0$ & 3 \\
\hline 18.3 .4$. c & $218010-3$ & 3 \\
\hline 18.3 .4$. d & $218948-8$ & 2 \\
\hline 18.3 .4$. e & $218949-6$ & 1 \\
\hline 18.3 .4$. f & $218013-8$ & 1 \\
\hline 18.4 .1$. a & $218014-6$ & 3 \\
\hline 18.4 .1$. b & $218015-4$ & 3 \\
\hline 18.4 .1$. c & $218016-2$ & 3 \\
\hline 18.4 .1$. d & $218017-0$ & 3 \\
\hline 184 d & $218018-9$ & 3 \\
\hline
\end{tabular}

Fonte: ANEXO II da NR-28 (1992)

Após a identificação do código de infração, é possível fazer o cruzamento com a quantidade de funcionários, para estimar o valor da multa de cada item infringido e o valor da multa total.

A multa possui um valor mínimo e um valor máximo, que varia de acordo com o nível de rigorosidade do fiscal em trabalho. O critério adotado na realização desse trabalho foi o do "valor mínimo" para os cálculos. Como os itens do Check-list são referentes à NR-18, apenas será utilizado o quadro de multas relacionadas à Segurança do Trabalho.

Quadro 3-Gradação das Multas

\begin{tabular}{|l|c|c|c|c|}
\hline $\begin{array}{c}\text { Número de } \\
\text { empregados }\end{array}$ & \multicolumn{4}{|c|}{ Segurança do Trabalho } \\
\hline & $\mathbf{I}_{1}$ & $\mathbf{I}_{2}$ & $\mathbf{I}_{3}$ & $\mathbf{I}_{4}$ \\
\hline $1-10$ & $630-729$ & $1129-1393$ & $1691-2091$ & $2252-2792$ \\
\hline $11-25$ & $730-830$ & $1394-1664$ & $2092-2495$ & $2793-3334$ \\
\hline $26-50$ & $831-963$ & $1665-1935$ & $2496-2898$ & $3335-3876$ \\
\hline $51-100$ & $964-1104$ & $1936-2200$ & $2899-3302$ & $3877-4418$ \\
\hline $101-250$ & $1105-1241$ & $2201-2471$ & $3303-3718$ & $4419-4948$ \\
\hline $251-500$ & $1242-1374$ & $2472-2748$ & $3719-4121$ & $4949-5490$ \\
\hline $501-1000$ & $1375-1507$ & $2749-3020$ & $4122-4525$ & $5491-6033$ \\
\hline mais de 1000 & $1508-1646$ & $3021-3284$ & $4526-4929$ & $6034-6304$ \\
\hline
\end{tabular}

Fonte: NR-28 (1992)

A Figura 6 apresenta exemplos de valores de gradação das multas, de acordo com o número de empregados, em Unidade Fiscal de Referência (UFIR). Em decorrência do estabelecido no parágrafo 3 o do Artigo 29 da medida provisória 2095 - 76, a UFIR foi extinta a partir do ano 2000. Sendo, a partir disso, seu valor fixado em $R \$ 1,0641$ (BRASIL, 2014).

O próximo passo foi identificar o custo de adequação de cada não conformidade encontrada. Dessa forma, foi possível fazer uma comparação entre 
o valor que deve ser investido para que a empresa de estudo consiga se adequar aos aspectos preconizados pelas NR-18 e o valor da multa a ser paga em uma fiscalização do Ministério do Trabalho e Emprego. O valor do custo de adequação será calculado através do TCPO, uma base de dados de composição de preços para orçamentos.

\section{RESULTADOS}

\section{ANÁLISE GERAL}

O gráfico 1 apresenta o nível de adequação médio, aos itens da NR-18 considerados no checklist de estudo, obtido por cada um dos trinta e um canteiros de obra analisados.

Gráfico 1 - Gráfico referente ao nível de adequação aos itens da NR-18 por canteiro

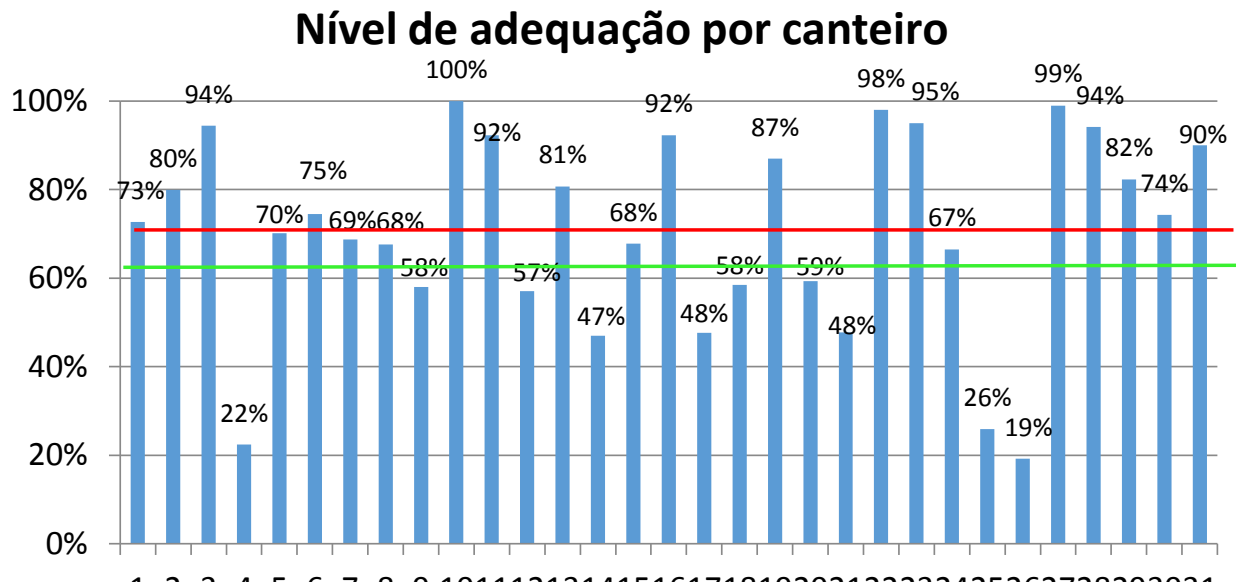

Fonte: A autora (2017)

Resumindo os dados quantitativos do gráfico 1 , foi possível concluir que a média geral de adequação obtida por todos os 31 canteiros de estudo foi de $71 \%$, representado pela linha vermelha, e o seu desvio padrão, ou seja, o erro do conjunto de dados foi de $23 \%$. Isso indica que em média, na cidade de Macaé, apenas um pouco mais da metade dos itens de segurança obrigatórios, presentes no checklist adotado, são cumpridos, o que corrobora as precárias condições de higiene e segurança do trabalho existentes no setor da construção civil e conseqüentemente o número alarmante de acidentes no setor (Ensslin et al., 2014).

Além disso, foi possível verificar que o maior índice de adequação encontrado foi de $100 \%$ (canteiro 10 ) e o menor e $19 \%$ (canteiro 26 ), que dentre todos os canteiros avaliados, dez apresentavam um nível de adequação abaixo do mínimo aceitável (60\%), representado pela linha verde e que, de acordo com o desvio padrão, os canteiros não possuem um comportamento muito uniforme entre eles.

Com o objetivo de melhor visualizar e compreender os dados coletados foi feita uma classificação das condições de trabalho de cada canteiro de estudo, a 
partir do seu nível de adequação médio, levando em consideração a metodologia adotada. 0 gráfico 2 mostra, dentre os 31 canteiros de obra analisados, quantos podem ser classificados como Ótimo, Bom, Regular, Ruim e Péssimo, considerando que cada denominação apresenta um intervalo de adequação prédeterminado.

Gráfico 2 - Número de canteiros em função da sua classificação

Classificação dos canteiros de obra

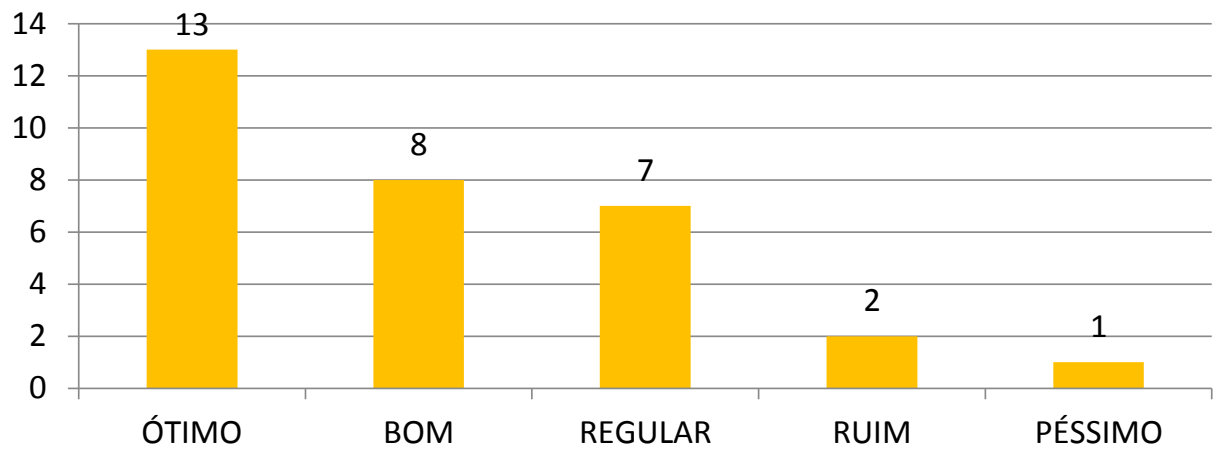

Fonte: A autora (2017)

\section{COMPARAÇÕES ENTRE RESULTADOS DE PESQUISAS ANTERIORES}

Outros estudiosos também realizaram pesquisas semelhantes, empregando o mesmo método utilizado nesta dissertação, com o intuito de descobrir o nível de adequação de canteiros de diversas cidades do Brasil e colaborar com melhorias que pudessem ser implantadas ou alteradas na NR-18 (SAURIM, 2000; MALLMANN, 2008; ALVARENGA, 2009; NORONHA, 2009; ASSMANN, 2015). Dessa forma, o gráfico 3 faz uma comparação entre os resultados encontrados por esses autores, com o resultado encontrado nesta pesquisa.

Gráfico 3 - Comparação entre resultados de pesquisas anteriores

\section{Nível de adequação por autor}

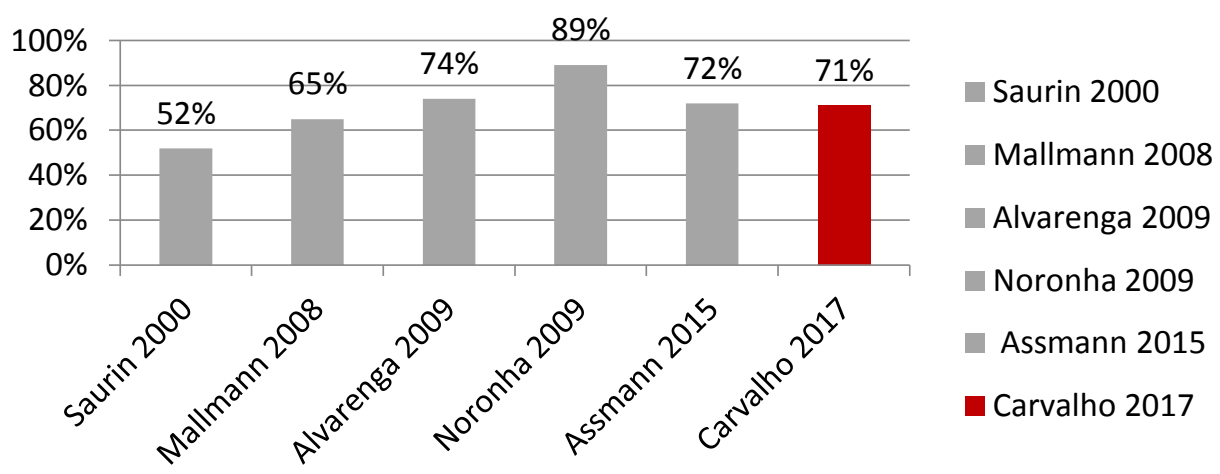

Fonte: A autora (2017)

A partir do gráfico 3 é possível notar que a média de adequação dos canteiros da cidade de Macaé não acompanha o crescimento que ocorreu entre 
os anos de 2000 e 2009. Dentre os fatos que possam justificar essa realidade, tem-se a falta de fiscalização e a grande quantidade de micro ou pequenas empresas em atuação na cidade.

Em relação à falta de fiscalização, isso vem ao encontro dos estudos realizados por Saurin et al., (2000), que mostra que as capitais dos Estados tendem a possuir um maior grau de implementação da NR-18 em seus canteiros, em relação às cidades do interior. Sabe-se que a Delegacia Regional do Trabalho, principal órgão de fiscalização do cumprimento das questões legais e normativas, possui um quadro funcional insuficiente para a execução adequada de seu trabalho, e essa situação se agrava nas cidades do interior (SAURIN et al., 2000).

Dessa forma, a menor atuação da fiscalização, também confirmada pelos responsáveis dos canteiros avaliados, pode justificar o desempenho da cidade de Macaé, quando comparado ao desempenho de outras cidades avaliadas por outros autores.

Em se tratando do porte das empresas, pela classificação do SEBRAE (2017), este estudo contou com as informações de 10 microempresas, responsáveis por 10 canteiros de obra, 11 pequenas empresas, responsáveis por 17 canteiros de obras, e 2 empresas médias, responsáveis por 4 canteiros de obra, como pode ser visto no gráfico 4. Dessa forma, podemos concluir que os dados utilizados nesta pesquisa provêm na sua grande maioria, aproximadamente $91 \%$, de micros e pequenas empresas.

Gráfico 4 - Número de empresas e canteiros avaliados em relação ao seu porte

\section{Quantidade de empresas e canteiros por porte}

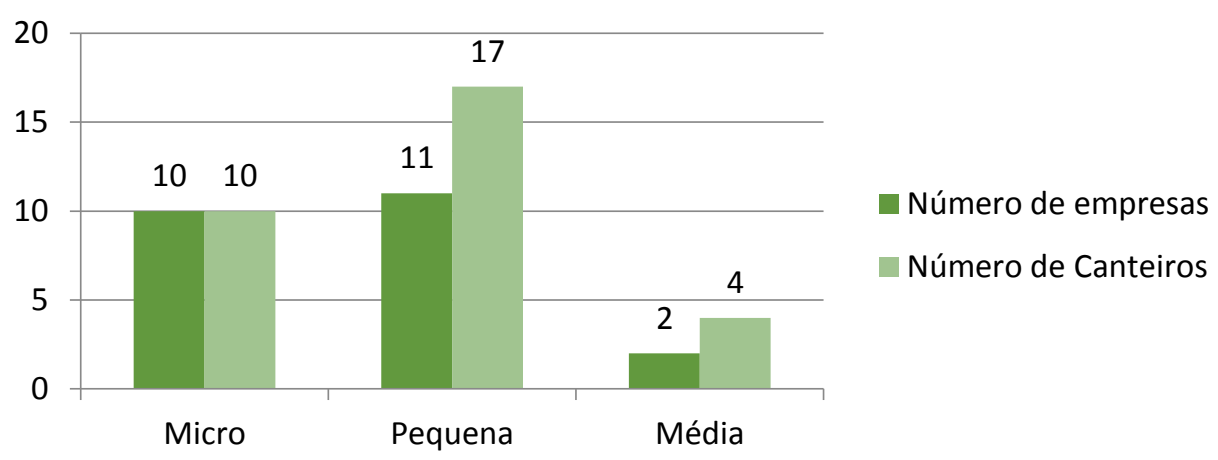

Fonte: A autora (2017)

Diversos estudos, entre os quais o Inquérito Europeu às Empresas e Riscos Novos e Emergentes (ESENER, 2017) da EU-OSHA, demonstram que os desafios, relacionados à gestão da saúde e segurança no trabalho (SST), são bastante significativos nas micro e pequenas empresas.

Essa gestão, relativamente deficitária, pode ser atribuída a características particulares das mesmas, tais como os elementos estruturais e organizacionais do trabalho e do emprego, a situação econômica e as relações laborais, a diversidade e a flexibilidade das empresas, o distanciamento face à regulamentação, as atitudes e competências dos proprietários e dos trabalhadores neste tipo de empresas ou o seu curto ciclo de vida. 
O gráfico 5 confirma essa maior dificuldade encontrada pelas micro e pequenas empresas em promover uma gestão adequada de saúde e segurança do trabalho, em relação ás empresas de médio porte.

Gráfico 5 - Nível de adequação médio à NR-18 por porte das empresas

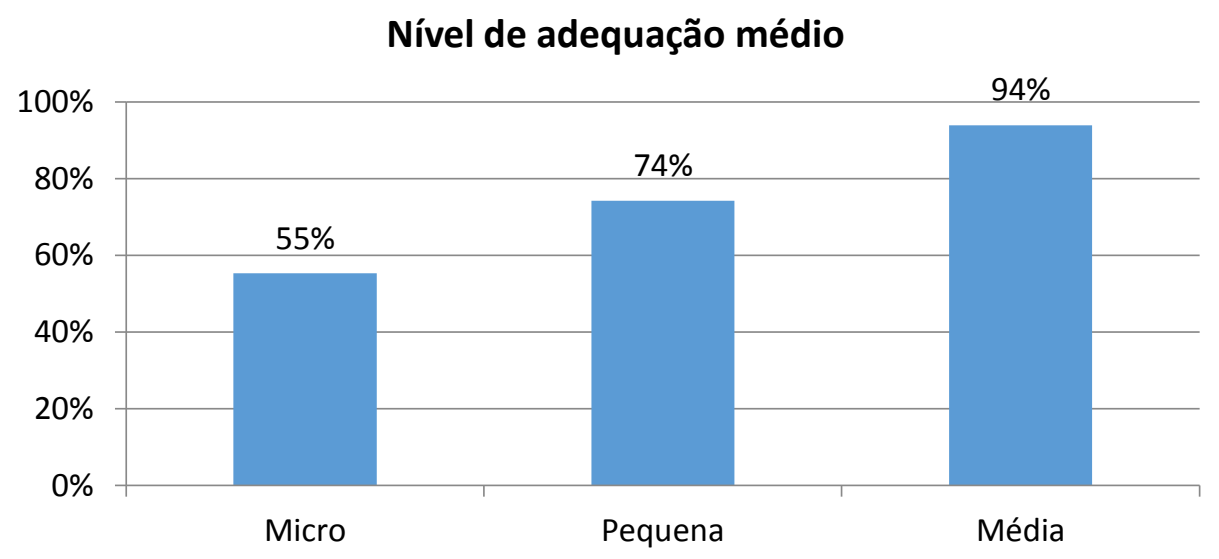

Fonte: A autora (2017)

Através do gráfico 5 é possível notar que as empresas de maior porte tendem a possuir um maior grau de cumprimento da NR-18, com destaque para as empresas de médio porte, as quais obtiveram uma média de adequação $94 \%$. Por outro lado, as microempresas apresentaram o menor índice de cumprimento da norma, obtendo uma adequação média de 55\%. Dessa forma, é presumível que o porte de uma empresa está diretamente relacionado ao seu nível de adequação ás normas de segurança.

\section{MULTAS E CUSTO DE ADEQUAÇÃO}

No que se refere à estimativa de multa a ser paga, por cada um dos 31 canteiros avaliados, pelas infrações aos preceitos regulamentadores sobre segurança e saúde do trabalhador, contemplados no checklist adotado, calculouse um valor médio de $\mathrm{R} \$ 38.710,54$. Já o somatório, de todas as multas a serem pagas, apresentou um valor aproximado de $R \$ 1.200 .026,76$.

Sabemos que o porte da empresa também interfere no valor da multa. Como conseqüência da grande quantidade de infrações cometidas pelas micro e pequenas empresas é possível constatar, através do gráfico 6, o elevado valor da multa média que devem ser imposta às mesmas. Em se tratando das micro empresas, o valor de sua multa representa, aproximadamente, quatro vezes o valor da multa média a ser paga pelas empresas de médio porte. Já as pequenas empresas, não ficam muito distantes dessa realidade, com uma multa média que representa, aproximadamente, três vezes o valor da multa das empresas médias.

A multa média a ser paga pelas empresas de médio porte apresenta um valor significativamente baixo, se comparado com o valor do empreendimento a ser construído. Em conversa e entrevistas abertas com os responsáveis pelas empresas de médio porte, foi constatado que, apesar de apresentarem um nível de adequação à Norma que pode ser classificado como "Ótimo", os responsáveis afirmaram que não se preocupam em adequar as não conformidades 
encontradas, pois, para eles, o pagamento da multa não teria impacto significativo nos custos do empreendimento.

Gráfico 6 - Valor da multa média a ser paga por canteiro em função do porte da empresa

\section{Multa média por porte}

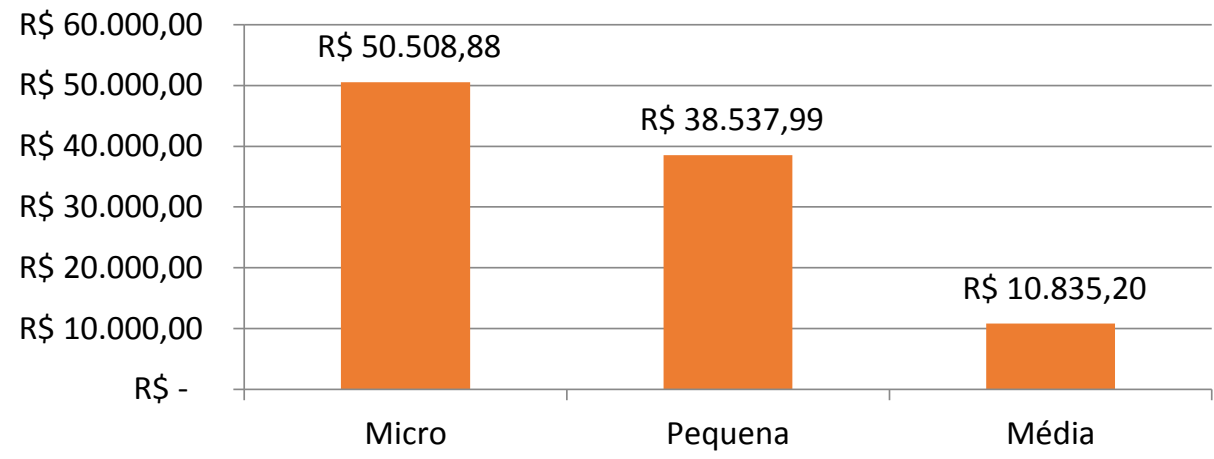

Fonte: A autora (2017)

Em relação ao custo de adequação das não conformidades encontradas nos canteiros de estudo, foi possível chegar a um valor médio estimado a ser pago de $\mathrm{R} \$ 12.232,19$. Já o somatório dos valores a serem investidos pelas empresas para que seus trabalhadores exerçam suas atividades com segurança foi de $\mathrm{R} \$ 379.197,88$.

Após análise crítica dos dados é possível evidenciar que o valor estimado da multa média a ser paga por um canteiro em uma possível fiscalização do Ministério do Trabalho (R\$38.710,54), representa aproximadamente três vezes o valor da estimativa de custo de adequação médio das não conformidades encontradas ( $R \$ 12.232,19)$, como mostra o gráfico 7.

Foi possível notar também, através dos dados, que todas as multas superaram o custo de adequação indicando que investir na redução ou eliminação dos riscos do trabalho custa menos para a empresa do que ficar sujeita ao pagamento de multas. Além disso, esses resultados evidenciam a ausência de conhecimento sobre o custo de se investir em segurança do trabalho e a falta de percepção das construtoras de sua importância, uma vez que muitas das exigências da norma são de baixo custo, breves e simples de serem executadas, como será confirmado na análise por categoria (SAURIN et al., 2000; ARAÚJO, 2000; FILGUEIRAS, 2015). 
Gráfico 7 - Comparação entre o valor médio da multa a ser paga e o custo de adequação das não conformidades

\section{Multa média X Custo de Adequação Médio}

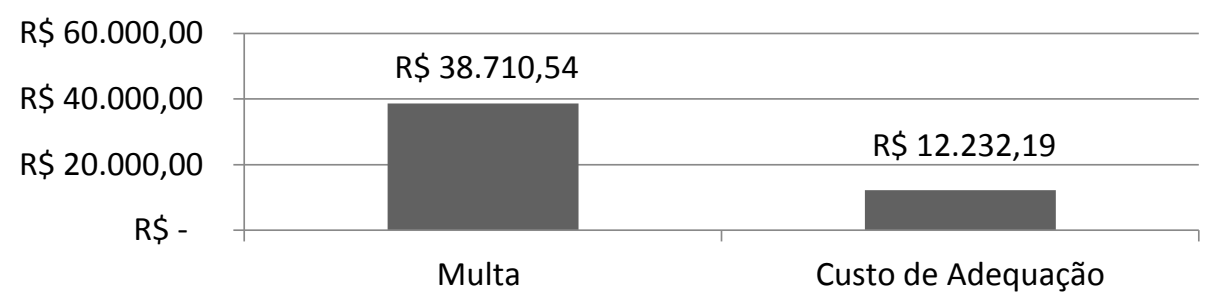

Fonte: A autora (2017)

\section{ANALISE DE CORRELAÇÃO LINEAR ENTRE A MULTA E O NÍVEL DE ADEQUAÇÃO}

Após confrontarmos os valores das multas a serem pagas, pelas não conformidades encontradas, com seus respectivos custos de adequação, buscouse estudar a relação existente entre as multas e o nível de adequação dos canteiros, ou seja, verificar até que ponto existe uma correlação entre essas duas variáveis.

O primeiro passo foi testar se as variáveis de estudo seguem uma distribuição normal e para isso foram calculadas as curtoses das duas distribuições de dados. Como o valor encontrado para as curtoses foi de 0,04115, para a variável nível de adequação, e $-0,77746$, para as multas, podemos dizer que ambas as distribuições de dados são normais. Dessa forma, foi possível realizar o cálculo do coeficiente de correlação de Pearson, para analisar a intensidade e a direção da relação linear entre as duas variáveis, o qual apresentou um valor de - 0,90819.

Este número demonstra uma forte relação entre as variáveis, devido ao seu valor absoluto ser próximo de 1 , e o seu sinal negativo indica a direção da relação, mostrando assim uma correlação negativa entre as variáveis. Ou seja, quanto maior o nível de adequação do canteiro à NR-18, menor será o valor da multa a ser paga pela empresa.

Como podemos ver no gráfico 8 , a linha que representa a correlação está inclinada para baixo, demonstrando então, esta correlação negativa. 
Gráfico 8 - Análise de correlação entre o nível de adequação por canteiro e sua respectiva multa

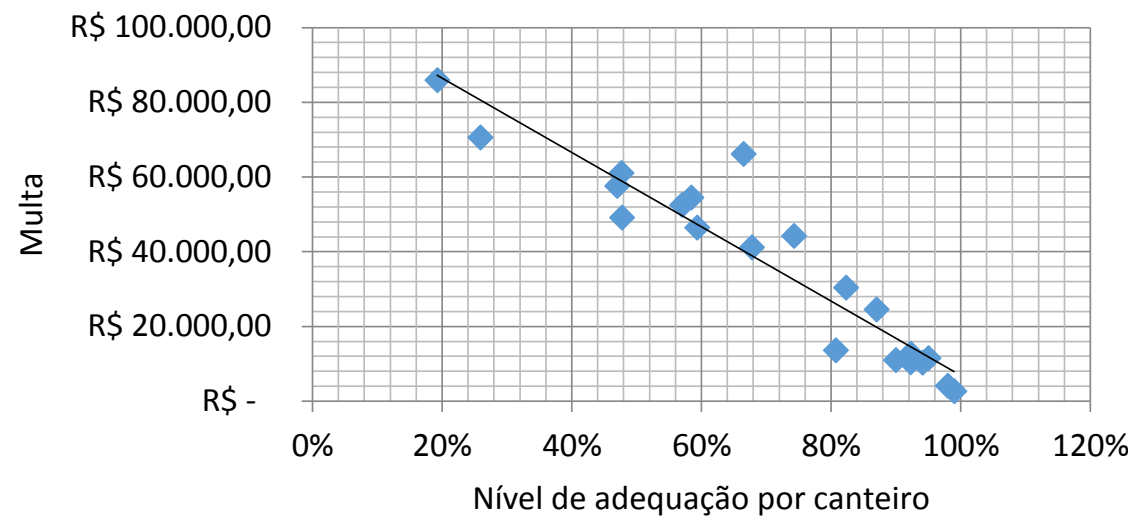

Fonte: A autora (2017)

\section{CONCLUSÃO}

A questão central que motivou a execução desta dissertação foi a necessidade de mudança no cenário de precariedade das condições de segurança do trabalho da indústria da construção civil, que acarreta a ocorrência de inúmeros acidentes no Setor.

Tendo consciência de que é possível prevenir esses atos indesejáveis e de forma a contribuir com essa mudança, buscou-se identificar e entender os elementos, presentes na Norma Regulamentadora 18 (NR-18), mais negligenciados pelas empresas da cidade de Macaé e demonstrar, de maneira quantitativa, que a segurança do trabalho não é um custo, mas sim investimento.

Após a realização de auditoria em 31 canteiros de obras de edificações residenciais e/ou comerciais, na cidade de Macaé, foi possível verificar que, apesar da média geral de adequação, aos requisitos da Norma Regulamentadora 18 , ter sido de $71 \%$, muitos trabalhadores exerciam suas funções em situações inseguras.

O nível de adequação médio encontrado foi justificado pela falta de fiscalização existente em cidades do interior e pela grande quantidade de micro ou pequenas empresas avaliadas.

O maior índice de adequação encontrado foi de $100 \%$ (canteiro 10), o menor de 19\% (canteiro 26) e dez canteiros de obra apresentaram um nível de adequação abaixo do mínimo aceitável (60\%). Os maiores problemas de segurança estavam relacionados à ausência ou insuficiência de medidas de proteção contra queda em altura, ao fornecimento de Equipamentos de Proteção Individual (EPI) e à falta de fiscalização do seu uso, além da carência de Sinalização de Segurança.

O somatório das multas a serem pagas pelas infrações, calculadas por canteiro, apresentou um valor aproximado de $\mathrm{R} \$ 1.203 .575,53$ e a multa média o valor de R\$38.825,02. Após o cálculo do coeficiente de correlação de Pearson, entre as multas e o nível de adequação dos canteiros, foi possível constatar que existe uma forte correlação entre essas duas variáveis, indicando que, quanto 
maior o nível de adequação do canteiro à NR-18, menor será o valor da multa a ser paga pela empresa.

Todas as multas, calculadas por canteiro, superaram o seu respectivo custo de adequação do ambiente de trabalho à NR-18. Além disso, após análise detalhada do custo de adequação de cada item infringido, foi possível constatar que grande parte das não conformidades existentes, provenientes tanto de atos inseguros dos trabalhadores, quanto de condições inseguras proporcionadas pelas empresas, são de custo baixo ou inexistente e de fácil adaptação.

Esse resultado evidencia a falta de cultura de segurança existente no setor da Construção Civil, além da falta de informação e preparo dos envolvidos nas obras. Pois, se houvesse uma conscientização dos benefícios de se investir em Segurança do Trabalho e sobre os custos e conseqüências do não cumprimento da NR-18, esse cenário poderia ser diferente.

Além de evitar o pagamento de multas, que podem prejudicar a imagem da empresa junto aos órgãos fiscalizadores e ao mercado, além da saúde financeira da empresa, o investimento em Segurança do Trabalho promove a melhoria da qualidade da gestão do empreendimento, da qualidade de vida do trabalhador, inibe perdas materiais e, o mais importante, evita acidentes. 


\title{
Auditing for the evaluation of non- conformities relating to NR-18 and its impact at undertakings of the sub-sector of buildings
}

\begin{abstract}
The Civil Construction industry is one of the sectors with the worst safety conditions and consequently the greatest number of accidents at work every year. Among the facts that justify this reality is the lack of compliance with the law or adequate safety regulations. Given this scenario, it is necessary for employers to become aware of the problem, implementing effective alternatives for their confrontation, among them the implementation of prevention programs. It is an indisputable fact that many accidents would be avoided if companies adopted the minimum safety principles in the Regulatory Standard NR-18. It establishes guidelines that aim at the implementation of control measures and safety preventive systems in the work environment of the Construction industry, which should be present in the physical arrangements of the beds. In this way, the present article aims to apply a qualitative tool in 31 construction sites in the city of Macaé, which contributes to the evaluation of critical elements in Civil Construction Industry Working Conditions Assessment Programs. In addition, quantify the possible fines to be paid for non-compliance with the NR-18 and make comparisons with the amount that must be invested so that the study companies can adapt their nonconformities, in order to prove that, on average, it is less costly for the company to invest in job security, than to be subject to the payment of fines that significantly increase the final costs of the enterprise.
\end{abstract}

KEYWORDS: Construction. Safety. NR-18. NR-28. 


\section{REFERÊNCIAS}

ABNT. ASSOCIAÇÃO BRASILEIRA DE NORMAS TÉCNICAS. NBR 18801 - Sistema de gestão da segurança e saúde no trabalho. Rio de Janeiro: ABNT, 2011.

ATLAS. Segurança e Medicina do Trabalho. 74a. ed. São Paulo: Atlas, 2014.

BLANCO, R. Modelo de controle de perdas aplicada a contrução civil: pontos críticos e perspectivas. Revista conhecimento e diversidade, La Salle.Niteroi, 2016.

BRASIL. Anuário Estatístico da Previdência Social (AEPS). Acidentes de Trabalho, 2015. Disponível em: http://www.previdencia.gov.br/wp-

content/uploads/2015/08/AEPS-2015-FINAL.pdf Acesso em: 17 fev. 2016

CAMPOS, A. CIPA - Comissão Interna de Prevenção de Acidentes: uma nova abordagem. 22ª ed. São Paulo: SENAC São Paulo, 2014.

CHIAVENATO, Idalberto. Gestão de Pessoas: o novo papel dos recursos humanos nas organizações. Rio de Janeiro: Campus, 1999.

DIEESE. Estudos e pesquisas. Estudo setorial da construção 2012. Disponível em: http://www.dieese.org.br/estudosetorial/2012/estPesq65setorialConstrucaoCivil 2012.pdf Acesso em: 08/01/2016.

ENSSLIN, S. R.; ENSSLIN, L.; MOREIRA, A. C. S.; PEREIRA, V. L. D. V. Avaliação da segurança do trabalho em empreendimentos da construção civil. Interciencia, v. 39, n. 1, p. 16-23, 2014.

FARROKHI, F. e MAHMOUDI- HAMIDABAD, A. (2012). Rethinking Convenience Sampling: Defining Quality Criteria. Theory and Practice in Language Studies, Vol. 2, No. 4, pp. 784-792, April 2012. crossref

FILGUEIRAS, V. A. et al. Saúde e Segurança do Trabalho na Construção Civil Brasileira. 1a ed., Sergipe: Procuradoria Regional do Trabalho da 20a região, 2015.

GURCANLI, G. E; BILIR, S; SEVIM, M. Activity based risk assessment and safety cost estimation for residential building construction projects. Safety Science, Volume 80, Dezembro de 2015, páginas 1-12. 
HEINRICH, H. W. Industrial accident prevention: a scientific approach. New York: Mac Graw Hill, 1959.

ILO - International Labor Organization. World of Work Report 2013. Geneve, 2014.

INSTITUTO BRASILEIRO DE GEOGRAFIA E ESTATÍSTICA -IBGE. Contas Nacionais, 2013. Diretoria de Pesquisas. Disponível em: http://www.ibge.gov.br. Acesso em 01 mar. 20016. IBGE. Indicadores conjunturais. Disponível em www.ibge.org.br.

IIDA, I. Ergonomia: projeto e produção. 2a edição revista e ampliada. São Paulo: Blucher, 2005.

MARTINS, M. S. Diretrizes para elaboração de medidas de prevenção contra quedas de altura em edificações. Dissertação (Mestrado em Engenharia Civil) Programa de Pós-Graduação em Engenharia Civil, Universidade Federal de São Carlos. São Carlos, 2004.

Ministério do Trabalho e Emprego. NR 18: Condições e Meio Ambiente de Trabalho na Indústria da Construção. Brasília, DF, 2016. Disponível em: <http://www.mte.gov.br> Acesso em 20.08.2016.

Ministério do Trabalho e Emprego. NR 28: Fiscalização e penalidades. Brasília, DF, 2016. Disponível em: <http://www.mte.gov.br> Acesso em 20.08.2016.

MTE - Ministério do Trabalho e Emprego et al. Anuário Estatístico de Acidentes do Trabalho: AEAT / 2014. Brasília: MTE, MPS, INSS, v.1., 868 p , (2015).

NUNES, T. A. Aplicabilidade da $\mathrm{nr} 18 \mathrm{em}$ canteiros de obras - estudos de caso em obras na cidade de santa maria/rs. 2016. Dissertação (Mestrado em Engenharia Civil) - Programa de Pós-Graduação em Engenharia Civil, Universidade Federal de Santa Maria, Rio Grande do Sul, 2016.

RAMAZZINI, M. (2015). Construção civil é líder em acidentes de trabalho. Disponível em: http://portal.anicer.com.br/2015/07/construcao-civil-tem-maiorindices-de-acidentes-no-trabalho/ Acesso em: 30/05/2016

RIGOLON, A. Aplicação de um Check List para Avaliação do Cumprimento Da Nr18 em um Canteiro de Obras. 2013. 76 f. Monografia (Especialização em Engenharia de Segurança do Trabalho) - Programa de Pós-Graduação em Engenharia de Segurança do Trabalho Universidade Tecnológica Federal do Paraná, Curitiba, 2013. 
SAURIN, T. A. Segurança e Produção: um modelo para o planejamento e controle integrado. Tese (Doutorado em Engenharia de Produção) - Programa de Pós-Graduação em Engenharia de Produção, Universidade Federal do Rio Grande do Sul, Porto Alegre, 2002.

SILVA, A. P. D. et al. A importância da gestão da segurança na construção civil com vistas à saúde, medicina do trabalho e conscientização dos trabalhadores: um estudo de caso na construtora c.v. Lopes Ltda. Franca: Centro Universitário de Franca, 2014. 14 p. Relatório de Pesquisa.

SIMON, B. Contribuições do PCMAT para a Indústria da Construção. Revista CIPA, n. 394, p. 34-56, jul. 2012.

ZARPELON, D., LEME, R., DANTAS, L. A NR-18 como instrumento de gestão de segurança, saúde, higiene do trabalho e qualidade de vida para os trabalhadores da indústria da construção. Monografia (Especialização em Engenharia de Segurança do Trabalho) - Programa de Pós-Graduação em Engenharia de Segurança do Trabalho, Universidade de São Paulo, São Paulo, 2008.

WAEHRER, G.M.; DONG, X.S.; MILLER, T.; HAILE, E.; MEN, Y., 2007. Costs of occupational injuries in construction in the united states. Accident Analysis \& Prevention, n.39, 1258-1266. crossref

WELTER, L. B. Sistema de Gestão de Segurança e Saúde do Trabalhador: Proposta Modelo para Aplicação na Construção Civil. 2014. 63 f. Monografia (Especialização em Engenharia de Segurança do Trabalho) - Curso de Pós Graduação em Engenharia de Segurança do Trabalho. Universidade Regional do Noroeste do Estado do Rio Grande do Sul, Ijuí, 2014.
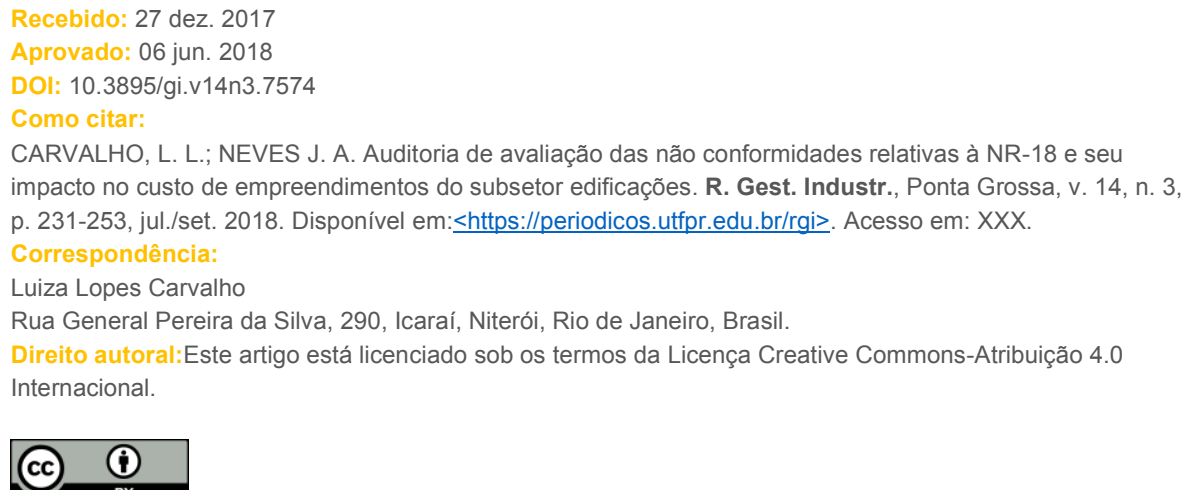